\title{
Anatomy of a disaster: one hospital's experience and recommendations
}

\author{
Walter D. Hogarth, MD;* Gordon F. Neil, MD†
}

\section{Introduction}

La prudence dicte que les hôpitaux aient un plan pour gérer les incidents à victimes multiples, mais peu d'entre nous croyons que nous aurons un jour à faire face à une véritable situation de catastrophe. Étant donné la myriade de problèmes de soins de santé plus pressants, les recommandations pour des exercices réguliers de planification en cas de sinistre sont souvent reléguées au bas de la liste des priorités. Or, lorsque l'hôpital régional de Red Deer a dû faire face récemment aux conséquences de la tornade de Pine Lake, la valeur d'une bonne planification en cas de sinistre a pris toute sa signification.

\section{Introduction}

Prudence dictates that hospitals have plans to deal with multiple casualty incidents, but few of us believe we will ever take part in an actual disaster response. Recommendations for the regular rehearsal of disaster plans often receive low priority, given the myriad of other pressing health care problems. Recently, however, when the Red Deer Regional Hospital (RDRH) was forced to deal with the aftermath of the Pine Lake tornado, the value of a well prepared disaster plan was reinforced.

\section{The setting}

Red Deer Regional Hospital, a 309-bed regional hospital, is located midway between Calgary and Edmonton, Alberta's 2 tertiary cardiovascular, thoracic and neurosurgical referral centres. RDRH has a substantial, but incomplete, complement of surgical specialties and accepts referrals from several smaller Central Alberta hospitals. The emergency department (ED) has 23 beds and functions at or above capacity most of the time, seeing approximately 50,000 patients annually.

\section{The event}

On Friday, July 14, 2000, at 1900 hours, an F3 tornado touched down at Pine Lake, Alberta, just 40 kilometres from Red Deer, and destroyed a popular campground. News of the tornado reached the hospital when victims began arriving by private vehicle. Moments later, the first emergency medical services (EMS) crew reached the scene and radioed confirmation. They estimated 50 "red" and 150 "yellow" victims, but others called in estimates ranging as high as 600 casualties, with 300 walking wounded and 150 "red" victims.

At 1945 hours, the RDRH disaster plan was activated. Hospital staff was called in using the hospital's paging system and by telephone fan-outs. The ambulance bay was converted to a triage area and the ED was cleared by admitting or discharging patients. Several patients discharged themselves when they heard the scope of the disaster, and 48 ward beds were cleared by discharging stable patients and issuing passes. A command centre was established in the admitting area adjacent to the ED and a manpower pool was set up in the auditorium. Because of the large number of severely injured patients anticipated, additional treatment areas were prepared in the OR recovery room, the day surgery and endoscopy areas, and the outpatient department. Additional supplies were brought to these areas.

\section{Victim arrival}

As is common in disasters, the first patients arrived early, by private vehicle, while the triage area was being organized and before the ED had been cleared. Close behind were the ground ambulances, carrying some of the most severely injured patients - mostly, victims of blunt trauma. An emergency physician and several ED nurses performed triage in the ambulance bay while admitting staff prepared a disaster chart for each victim. Charts stayed with patients, on the stretcher, until admission to a ward or discharge. "Red" victims (head and chest injuries), went to the ED and OR recovery room, "yellow" victims (multiple orthopedic injuries and significant wounds) went to the day surgery and endoscopy areas and "green" patients (isolated orthopedic injuries and lacerations) went to the outpatient depart- 
ment. These victims were moved efficiently to their defined treatment areas.

Air ambulances soon began arriving. Unfortunately, because RDRH is built on a hill and there is no suitable landing site near the ED, the helipad is at the opposite end of the hospital, necessitating long stretcher trips through the hospital - against the normal patient flow. This precluded appropriate triage and caused problems with admitting documentation. When the problem became apparent, a makeshift helipad was constructed by removing the vehicles and light standards from the ED parking; however, this work was not completed in time for the helicopters arriving from Pine Lake. In total, 85 victims, including 20 red, 35 yellow and 30 green, were seen and treated before midnight. Of these, 29 were admitted and 9 were transferred to tertiary care centres.

\section{Hospital staff}

Soon after disaster activation, ward nursing staff moved to the ED, leaving inpatient units poorly covered. An ineffective fan-out process had physicians phoning or arriving in the crowded ED, wondering what was going on and how they could help. Physicians and nurses arrived from other communities to offer their assistance — often with no means of confirming their identity or qualifications. As physicians and nurses arrived, they were assigned to specific areas. Surgeons staffed the red and yellow areas, and they triaged patients to the operating rooms. Medical consultants discharged stable patients and readied beds in the intensive care unit. Family physicians worked in the yellow and green areas. One emergency physician oversaw each treatment area and the rest were distributed as needed. In addition, an emergency physician was designated as the coordinator of physician resources and as the transfer liaison. This physician was not involved in direct patient care but this position was extremely worthwhile in maintaining patient flow. Radiologists expedited patient care by immediately interpreting all studies and writing their interpretation on the film folder.

\section{Ancillary areas}

A centre for relatives of the victims was set up in a nearby elementary school. Unfortunately, the site had too few telephones and a poor computer link to the hospital. As a result, relatives endured long waits to use a telephone and to obtain information about their injured family members. Other areas that were outlined in the disaster plan, including a childcare centre (for children of staff) and a discharge holding area (for inpatients, ED patients and discharged disaster victims forced to rapidly vacate their beds), were never set up. The lack of a childcare centre necessitated that the spouses of some staff members supervised the children of others who came to help.

\section{External communication}

Accurate information from the disaster scene was scarce during the early hours after the tornado strike. After the initial estimate of 50 red and 150 yellow victims there were only a few calls from the scene requesting that we accept further patients. Because there was only one telephone line into the hospital's command centre, these calls came instead to the ED.

Early on, one of the tertiary referral sites received notification from the scene that they should prepare for 150 red patients. The hospital rapidly cleared 130 inpatient beds in anticipation of these victims, then phoned to offer us physicians and nurse support. They are to be commended for their rapid mobilization.

\section{Internal communication}

Within the hospital there were several communication problems. Some ancillary areas needed computer installation and phone hookup, which led to delays. Overhead pages were not audible in all areas of the hospital. Some staff members lacked identifying hats or uniforms, therefore were not identifiable to other staff. Nursing staff who were manning the phones received incomplete information from the emergency physician coordinator, and it was difficult to get accurate information on the status of the victim treatment areas without physically visiting them. Therefore, ED staff lacked up-to-date information on hospital resource availability when requests to transfer patients from the scene arrived.

\section{Transfers}

Nine patients were transferred to tertiary care centres. In some cases, confusion arose when RDRH staff and air ambulance personnel independently made different transfer arrangements to different destinations - neither being aware of what the other was doing. For example, after arranging ground transport for some patients, hospital staff learned that helicopters were already preparing to shuttle the same patients to the local airport, where fixed-wing planes were waiting to transfer them to the tertiary care centres. On more than one occasion, relatives were told that a patient was being sent to one city when, in fact, they were routed to the other.

\section{Crowd control and public relations}

Many relatives and family members entered the hospital through the emergency and main entrances before these 
were secured. We were subsequently forced to remove them from the ED and sequester them in the radiology waiting room.

The RDRH command centre handled all calls from the public and the media, but shut down at 0400 , only 8 hours after the disaster. Unfortunately, the telephone number that the hospital provided for the Red Cross was not their disaster number, and the line was staffed only during business hours. Consequently, the ED - already swamped — was forced to deal with large numbers of calls from relatives trying to locate victims.

\section{Teaching points}

1. Review and exercise the disaster plan regularly. RDRH's last full-scale disaster exercise, including moulage patients, was in 1992; however, in the interim, several components of the plan had been tabletop tested.

2. Think through the aspects of the plan that cannot be tested during an exercise.

Shortfalls in our plan included crowd control, communication with outside agencies and the establishment of discharge holding areas and centres for relatives.

3. Pre-assign hospital staff to specific treatment areas. Make sure they know where to respond to if a disaster is called; this limits confusion and overcrowding in the $\mathrm{ED}$ and allows for faster staffing of the treatment areas. Although this was defined in our hospital's disaster plan, some staff were unfamiliar with their expected response when the time came.

4. Identify key players at your hospital who will communicate with in-house treatment areas, disaster-scene responders and other participating hospitals.

Our ED received calls from the disaster scene, but we had limited information regarding the capacity of treatment areas within the hospital, including the operating room and support services. This made it difficult to determine our ability to accept further patients.

5. Have discussions with fire, police, EMS and any other prehospital providers who will be involved in disaster response in your area. Determine how you will establish 2-way communication with the scene.

6. We strongly recommend that a standard provincial or regional disaster communication system, accessible to all responders, be developed.
7. Discuss with transfer services and receiving hospitals the most efficient way to arrange multiple transfers over a short time period.

8. Secure your hospital early to prevent an onslaught of relatives and sightseers.

9. Provide a site where relatives can congregate and receive accurate, up-to-date information.

Our relative centre was offsite and had inadequate communication and information links.

10. Take time to capture demographic data at the time of triage.

Although each of our patients had a disaster chart that followed them through their hospital course, they were identified primarily by their disaster number and names were not always collected. This made it difficult to identify patients and to communicate with outside agencies, other hospitals and the centre for relatives.

11. Keep adequate supplies on-site. In multiple-casualty incidents, specific supplies will be predictably consumed. In this disaster, which involved multiple blunt trauma victims, chest tube equipment and cervical spine immobilization packages quickly became scarce. Our hospital is adding disposable sets to its disaster equipment.

12. Consider replacing the standard coloured triage cards with coloured arm bands. Arm bands would be more reliable, as long as they can be coordinated with local emergency medical services providers.

Triage cards leave much to be desired. They frequently became separated from the patient and they were unreadable in wet conditions.

\section{Summary}

All physicians hope that their hospital is prepared to respond in the event of a disaster. We also hope a disaster will never occur. In this instance, a regional hospital was able to handle the patient care efficiently and competently under trying circumstances. Further refinement of the disaster plan will allow for smoother and more confident management of future disasters.

Correspondence to: Dr. Walter Hogarth, Red Deer Physicians Emergency Services Ltd., Rm. 10, Administration Wing, Red Deer Regional Hospital Centre, 3942 50A Ave., Red Deer AB T4N 4E7; 403 342-2342, fax 403 343-4459, whogarth@telusplanet.net 